\title{
Tolerability and Safety of Souvenaid in Patients with Mild Alzheimer's Disease: Results of Multi-Center, 24-Week, Open-Label Extension Study
}

\author{
Marcel G.M. Olde Rikkert ${ }^{\mathrm{a}, *}$, Frans R. Verhey ${ }^{\mathrm{b}}$, Rafael Blesa $^{\mathrm{c}}$, Christine A.F. von Arnim ${ }^{\mathrm{d}}$, \\ Anke Bongers ${ }^{\mathrm{e}}$, John Harrison ${ }^{\mathrm{f}}$, John Sijben ${ }^{\mathrm{e}}$, Elio Scarpini ${ }^{\mathrm{g}}$, Maurits F.J. Vandewoude ${ }^{\mathrm{h}}$, Bruno Vellas ${ }^{\mathrm{i}}$, \\ Renger Witkamp ${ }^{\mathrm{j}}$, Patrick J.G.H. Kamphuis ${ }^{\mathrm{e}}$ and Philip Scheltens ${ }^{\mathrm{k}}$ \\ ${ }^{a}$ Radboud Alzheimer Centre, Department of Geriatric Medicine, Radboud University Hospital, Nijmegen, \\ The Netherlands \\ ${ }^{\mathrm{b}}$ Alzheimer Centre Limburg, Maastricht University Medical Centre, Maastricht, The Netherlands \\ ${ }^{\mathrm{c}}$ Department of Neurology, Hospital de la Sta Creu i St. Pau, Barcelona, Spain \\ ${ }^{\mathrm{d}}$ Department of Neurology, Ulm University, Ulm, Germany \\ ${ }^{\mathrm{e}}$ Nutricia Advanced Medical Nutrition, Nutricia Research, Utrecht, The Netherlands \\ ${ }^{\mathrm{f}}$ Metis Cognition Ltd, Kilmington, UK \& Imperial College, London, UK \\ $\mathrm{g}$ University of Milan, Fondazione Cà Granda, IRCCS Ospedale Policlinico, Milan, Italy \\ ${ }^{\mathrm{h}}$ University Department of Geriatrics, Antwerp Hospital Network (ZNA St Elisabeth), University of Antwerp, \\ Belgium \\ ${ }^{\mathrm{i}}$ Gerontopole, INSERM U 1027, Toulouse, France \\ ${ }^{\mathrm{j}}$ Division of Human Nutrition, Wageningen University, Wageningen, The Netherlands \\ ${ }^{\mathrm{k}}$ Alzheimer Center, VU University Medical Center, Amsterdam, The Netherlands
}

Handling Associate Editor: Thomas Shea

Accepted 2 September 2014

Abstract.

Background: The medical food Souvenaid, containing the specific nutrient combination Fortasyn Connect, is designed to improve synapse formation and function in patients with Alzheimer's disease (AD). Two double-blind randomized controlled trials (RCT) with Souvenaid of 12 and 24 week duration (Souvenir I and Souvenir II) showed that memory performance was improved in drug-naive mild AD patients, whereas no effects on cognition were observed in a 24-week RCT (S-Connect) in mild to moderate AD patients using AD medication. Souvenaid was well-tolerated in all RCTs.

Objective: In this 24-week open-label extension (OLE) study to the 24-week Souvenir II RCT, long-term safety and intake adherence of the medical food Souvenaid was evaluated.

Methods: Patients with mild AD $(n=201)$ received Souvenaid once-daily during the OLE. Main outcome parameters were safety and product intake adherence. The memory domain z-score from a revised neuropsychological test battery was continued as exploratory parameter.

Results: Compared to the RCT, a similar (low) incidence and type of adverse events was observed, being mainly (68.3\%) of mild intensity. Pooled data (RCT and OLE) showed that 48-week use of Souvenaid was well tolerated with high intake adherence $(96.1 \%)$. Furthermore, a significant increase in the exploratory memory outcome was observed in both the active-active and control-active groups during Souvenaid intervention.

\footnotetext{
*Correspondence to: Marcel Olde Rikkert, MD, PhD, Radboud Alzheimer Center, Department of Geriatric Medicine, Radboud University Hospital, P.O. Box 9101, 6500 HB Nijmegen,
}

The Netherlands. Tel.: +312436167 72; Fax: +312436174 08; E-mail: M.Olde-Rikkert@ger.umcn.nl. 
Conclusion: Souvenaid use for up to 48-weeks was well tolerated with a favorable safety profile and high intake adherence. The findings in this OLE study warrant further investigation toward the long-term safety and efficacy of Souvenaid in a well-controlled, double-blind RCT.

Keywords: Alzheimer's disease, clinical trial, dietary management, intervention studies, long-term, medical nutrition therapy, memory, patient adherence, safety

\section{INTRODUCTION}

Progressive synaptic dysfunction and synapse loss are key hallmarks of Alzheimer's disease (AD) [1-3]. They are present from the very early stages of the disease, even before the emergence of clinical symptoms [4], and strongly correlate with cognitive deterioration [5]. As such, synaptic dysfunction is a useful target for interventions in $\mathrm{AD}$.

In animal models, dietary enrichment of nutrients that are precursors of synaptic membrane phospholipids can enhance phosphatide synthesis [6], the number of dendritic spines, and the levels of pre- or post-synaptic proteins [7], which are all prerequisites for new synapse formation. Further, preclinical studies showed that administration of specific combinations of the phospholipid synthesis-promoting nutrients can enhance neurotransmission and cognitive function [8-11], which are indicative of improved synaptic function. These and other observations, together with the notion that the circulating levels of these nutrients are lower in AD compared with healthy controls [12, 13], led to the creation of the specific nutrient combination Fortasyn ${ }^{\circledR}$ Connect. This comprises the precursors and cofactors for the synthesis of neuronal membranes, and is designed to support synapse formation and function in patients with $\mathrm{AD}$ [14]. In order to test the hypothesis that administering these nutrients enhances synaptic function and ameliorates cognitive symptoms in $\mathrm{AD}$, the medical food Souvenaid ${ }^{\circledR}$ (Nutricia N.V., Zoetermeer, The Netherlands), which contains Fortasyn Connect, was developed.

Memory loss is an important clinical manifestation in early $\mathrm{AD}[15,16]$, and may be the result of synaptic loss in specific areas of the brain [17]. Memory performance was therefore selected as a (co-)primary outcome in two double-blind randomized controlled trials (RCTs) with Souvenaid in drug-naive patients with mild AD ('Souvenir I' and 'Souvenir II'). These studies both showed that Souvenaid statistically significantly improved memory performance, which may be related to disease specific nutrient requirements $[18$, 19]. In addition, cognitive performance was selected as primary outcome in a double-blind RCT in patients with mild-to-moderate $\mathrm{AD}$ receiving standard-care $\mathrm{AD}$ medication ('S-Connect), showing that 24-week use of Souvenaid did not slow cognitive decline in these patients [20].

It was postulated that the nutrient levels provided by once-daily use of Souvenaid are within a safe range of intake, and that Souvenaid therefore would be well tolerated. This was supported by the results of Souvenir I and Souvenir II $[18,19]$ as well as the add-on SConnect study [20]. In addition, the 24-week product intake adherence was high in all these studies $(\geq 94 \%)$ [18-20].

While these data provide evidence that Souvenaid is well tolerated, the intervention period of the studies presented so far is limited to 24 weeks. The study presented here is a 24-week open-label extension (OLE) to the Souvenir II RCT, designed to evaluate the longterm safety and compliance to Souvenaid in patients with mild AD. In addition, the study explored the longterm impact of Souvenaid on memory performance in an uncontrolled design.

\section{MATERIAL AND METHODS}

\section{Study setting}

Twenty-six out of the 27 AD centers that recruited participants for the RCT also recruited participants for the OLE study. In the center that did not include study participants, none of the three potentially eligible patients were willing or able to continue in the OLE study. The ethics committee of each participating center reviewed and approved the protocol. The study was conducted in accordance with the Declaration of Helsinki and the International Conference on Harmonisation of Good Clinical Practice guidelines as appropriate to nutritional products and legislation of the country in which the research was conducted.

\section{Participants}

The patient population of the multi-center, multicountry Souvenir II RCT has been reported previously [19]. Briefly, major eligibility criteria included: 1) being drug-free for $\mathrm{AD}$ medication; 2) a probable diagnosis of AD (National Institute of Neurological 
Disorders and Stroke-Alzheimer's Disease and Related Disorders Association [21]); and 3) mild AD as defined by a Mini-Mental State Examination (MMSE) [22] score of $\geq 20$. Following completion of the RCT, patients willing to continue into the OLE study were required to have a responsible caregiver available, and both had to reconfirm their written informed consent. Exclusion criteria included the use of other investigational products, alcohol or drug abuse in the opinion of the investigator, or the investigator's uncertainty about the willingness, ability, or medical status of the patient to comply with the protocol. Eligibility criteria for the OLE allowed patients to use nutritional supplements and/or AD medication, thereby reflecting a more reallife clinical setting.

\section{Study design}

All patients originally randomly assigned to active (Souvenaid) or control product who completed the 24-week, double-blind RCT (Dutch Trial Registration number NTR1975) were eligible to participate in the 24-week OLE study (Dutch Trial Registration number NTR2571). In the OLE, all patients received the active product once-daily in the form of a $125 \mathrm{ml}$ drink (vanilla or strawberry flavor). The active product contains the specific nutrient combination Fortasyn Connect, comprising $625 \mathrm{mg}$ uridine monophosphate, $400 \mathrm{mg}$ choline, $106 \mathrm{mg}$ phospholipids, $1200 \mathrm{mg}$ docosahexaenoic acid (DHA), $300 \mathrm{mg}$ eicosapentaenoic acid (EPA), $40 \mathrm{mg}$ vitamin $\mathrm{E}(\alpha-$ tocopherol equivalents), $80 \mathrm{mg}$ vitamin $\mathrm{C}, 60 \mu \mathrm{g}$ selenium, $1 \mathrm{mg}$ vitamin $\mathrm{B} 6,3 \mu \mathrm{g}$ vitamin $\mathrm{B} 12$, and $400 \mu \mathrm{g}$ folic acid) per $125 \mathrm{ml}$, in addition to other vitamins, minerals, trace elements, and macronutrients. Study staff, patients, and caregivers remained blinded to the patient's initial randomized study group allocation throughout the 48 weeks. The screening/baseline visit for the OLE study was combined with the final visit (Week 24) of the RCT. Study parameters were assessed at the screening/baseline visit, at Week 12 (presented as Week 36), and 24 (presented as Week 48). Adverse events (AEs) and changes in concomitant medication and nutritional supplements were recorded every six weeks. Recording of product intake was performed daily.

\section{Outcome measures}

The main outcome measures of the OLE study were safety and product intake adherence. Safety assessments included the recording of (serious) AEs
([S]AEs), and the monitoring of vital signs and laboratory parameters. Product intake adherence was measured by studying caregiver-supervised patientreported daily diaries, in which was recorded whether the patient did or did not take the study product on each particular day. A product evaluation questionnaire (7point Likert scale; 1 = "dislike it very much", 7 = "like it very much") was also completed by the patient to assess the appreciation of the taste and convenience of the product.

At the start of the OLE study, a new MMSE assessment was performed for the characterization of the study population. All other patient characteristics were derived from the Souvenir II RCT. The primary outcome of the RCT, the memory domain composite $\mathrm{z}$-score, was assessed as exploratory outcome in the OLE. This domain is based on the Neuropsychological Test Battery (NTB) [23] and consists of Rey Auditory Verbal Learning Test immediate recall, delayed recall and recognition performance, and Wechsler Memory Scale-revised verbal paired associates immediate and delayed recall. In addition, the Disability Assessment for Dementia scale [24] was an exploratory outcome for functional ability. Study staff performing the assessments received appropriate training on outcome assessments via a study specific test manual. In addition, local rater trainings were provided for the assessment of the neuropsychological tests. Other parameters included specific nutritional blood markers (plasma vitamin E, erythrocyte DHA and EPA, and plasma homocysteine). Venous blood samples were taken, processed, and stored in a $-80^{\circ} \mathrm{C}$ freezer until batch shipped on dry ice. After extracting lipids from erythrocyte membranes, the fatty acid profile in erythrocyte membranes was assayed by gas chromatography. Plasma vitamin E levels were measured using high performance liquid chromatography to determine content of alpha-tocopherol. Homocysteine levels (free and protein-bound) were measured using high performance liquid chromatography with fluorescence detection after preparing a derivate $[25$, 26].

\section{Statistical analyses}

Analyses were performed on all available data from patients participating in the OLE study. OLE data are presented according to the intervention received during the double-blind study period (control-active and active-active). The following (differences in) effects on the exploratory NTB memory domain scores were statistically tested: a) between-group comparisons 
including control-active group versus active-active group in the total 48 week and 24-48 week intervals and the comparison of the baseline-24 week interval in the active-active group versus the $24-48$ week interval in the control-active group, and b) within-group comparisons including within the control-active group the comparison of the active intervention (week 24-48) versus control intervention (baseline-week 24), within the active-active group the comparison of the baselineweek 24 interval versus the week 24-48 interval and both within the control-active and active-active groups the change from 24 to 48 weeks. In addition, two exploratory key groups of interest were defined for the analysis of effects on the NTB memory domain score: 1) patients who did not start using AD medication during the OLE study, and 2) patients with a large study gap. See supplementary material for detailed information.

Comparisons were statistically tested using $t$-tests and/or by using a mixed model for repeated measures (MMRM) in which time was treated as a categorical variable and represented by dummies. Correction for multiple testing was not applied due to the explorative nature of this study, the small sample size, and the high correlation between outcome parameters.

Statistical analyses were performed using $\mathrm{SAS}^{\circledR}$ statistical software (SAS Enterprise Guide 4.3 for Windows, SAS Institute Inc., Cary, NC, USA).

\section{RESULTS}

\section{Patient demographics}

A total of 259 patients were originally randomized to receive either active or control product for 24 weeks in the double-blind RCT. Of the 238 patients (92\%) who completed the RCT, 201 patients $(84.5 \%)$ entered the OLE study between July 2010 and October 2011 (Fig. 1). The overall discontinuation rate during the OLE study was $7.5 \%$ (15 patients). Seven (3.5\%) patients discontinued due to (S)AEs: 6 patients in the control-active group (enlarged abdomen, bronchitis, avascular bone necrosis, impaired concentration, malignant lymphoma, and diarrhea), and one patient in the active-active group (diverticula). Of these (S)AEs, only diarrhea was considered to be related to the use of the study product. Additional reasons for discontinuation included withdrawal of informed consent (2 patients), loss to follow-up (3 patients), and 'other' (3 patients).

Baseline characteristics for the study populations enrolled in the double-blind RCT and in the OLE study are summarized in Table 1 . The mean age of the patients in the OLE study was $74.2( \pm 7.6)$ years, $51 \%$ of patients were male and the mean MMSE score was $25.1( \pm 3.3)$, representing a population with very mild $\mathrm{AD}$. Baseline characteristics of patients who

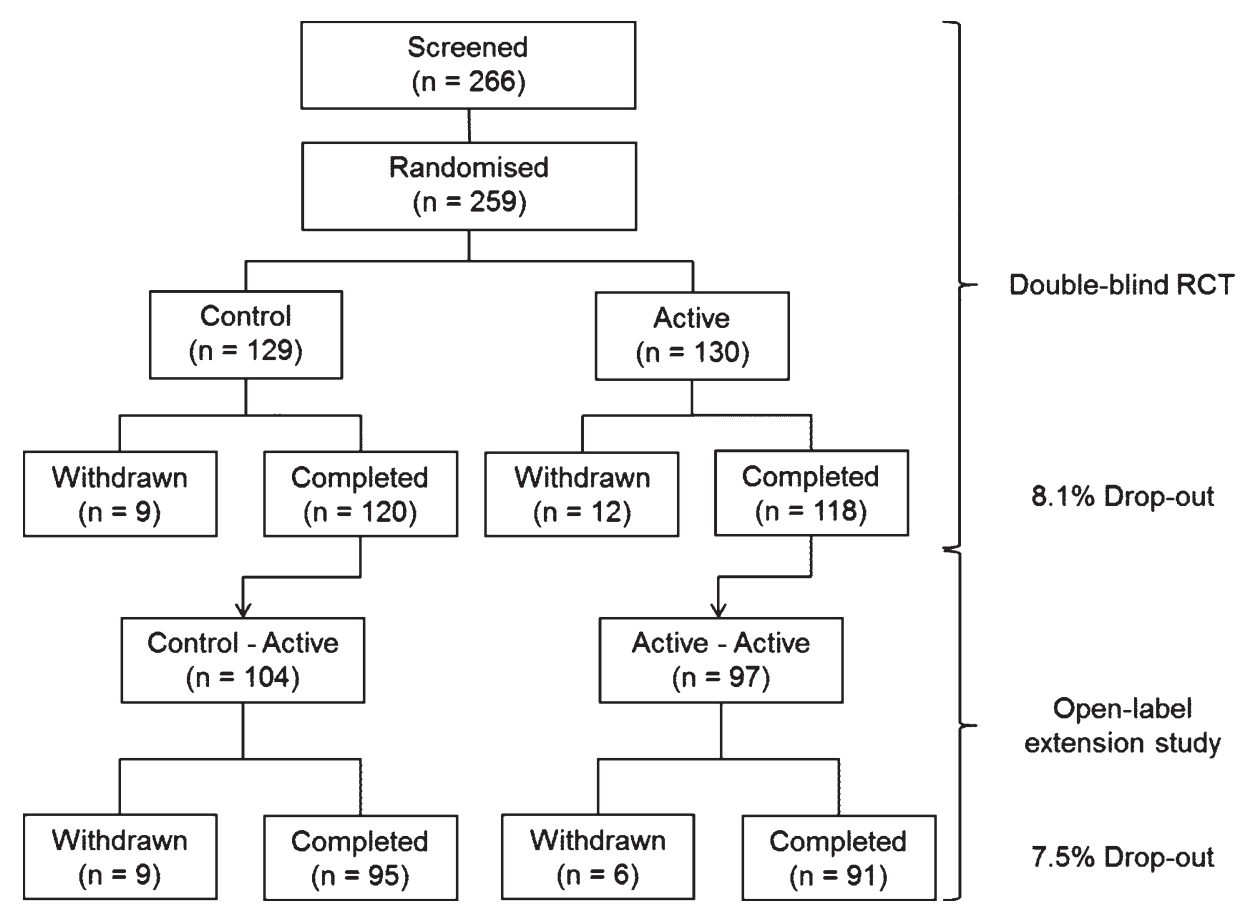

Fig. 1. Subject flow. 
Table 1

Baseline characteristics of the Souvenir II RCT population and for patients (not) continuing in the OLE

\begin{tabular}{|c|c|c|}
\hline & Control(-Active) & Active(-Active) \\
\hline \multicolumn{3}{|l|}{$\begin{array}{l}\text { Souvenir II RCT } \\
\quad \text { intent-to-treat population }\end{array}$} \\
\hline $\mathrm{n}$ & 129 & 130 \\
\hline Male, n (\%) & $64(49.6)$ & $68(52.3)$ \\
\hline Age, years & $73.2(8.4)$ & $74.4(6.9)$ \\
\hline BMI, $\mathrm{kg} / \mathrm{m}^{2}$ & $26.7(4.2)$ & $26.1(4.1)$ \\
\hline $\begin{array}{l}\text { Years of education beyond } \\
\text { primary school }\end{array}$ & $6.6(4.6)$ & $6.5(4.8)$ \\
\hline $\begin{array}{l}\text { Duration of AD since } \\
\text { diagnosis, months, } \\
\text { median [range] }\end{array}$ & $2.0[0.0-88.0]$ & $1.0[0.0-70.0]$ \\
\hline \multicolumn{3}{|l|}{ ApoE $\varepsilon 4$ carrier, n (\%) } \\
\hline No & $58(49.2)$ & $62(51.2)$ \\
\hline Yes & $60(50.8)$ & $59(48.8)$ \\
\hline Unknown & 11 & 9 \\
\hline Total MMSE score & $25.0(2.8)$ & $24.9(2.9)$ \\
\hline \multicolumn{3}{|l|}{$\begin{array}{l}\text { Souvenir II RCT completers } \\
\quad \text { enrolled in OLE }\end{array}$} \\
\hline $\mathrm{n}$ & 104 & 97 \\
\hline Male, $n(\%)$ & $52(50.0)$ & $51(52.6)$ \\
\hline Age, years ${ }^{\dagger}$ & $73.9(8.3)$ & $74.5(6.8)$ \\
\hline $\mathrm{BMI}, \mathrm{kg} / \mathrm{m}^{2} \dagger$ & $27.3(4.2)$ & $26.9(4.2)$ \\
\hline $\begin{array}{l}\text { Years of education beyond } \\
\text { primary school }\end{array}$ & $6.7(4.7)$ & $6.2(4.8)$ \\
\hline $\begin{array}{l}\text { Duration of AD since } \\
\text { diagnosis, months, } \\
\text { median [range] }\end{array}$ & $2.0[0.0-88.0]$ & $1.0[0.0-70.0]$ \\
\hline \multicolumn{3}{|l|}{ ApoE $\varepsilon 4$ carrier, n (\%) } \\
\hline No & $46(48.9)$ & $41(44.1)$ \\
\hline Yes & $48(51.1)$ & $52(55.9)$ \\
\hline Unknown & 10 & 4 \\
\hline $\begin{array}{l}\text { Total MMSE score - Start } \\
\text { RCT }\end{array}$ & $25.1(2.9)$ & $25.0(2.8)$ \\
\hline $\begin{array}{l}\text { Total MMSE score - Start } \\
\text { OLE }\end{array}$ & $25.1(3.4)$ & $25.1(3.3)$ \\
\hline \multicolumn{3}{|l|}{$\begin{array}{l}\text { Souvenir II RCT completers } \\
\text { not enrolled in OLE }\end{array}$} \\
\hline$n$ & 16 & 21 \\
\hline Male, $n(\%)$ & $6(37.5)$ & $10(47.6)$ \\
\hline Age, years ${ }^{\dagger}$ & $72.1(8.7)$ & $76.7(5.8)$ \\
\hline $\mathrm{BMI}, \mathrm{kg} / \mathrm{m}^{2} \dagger$ & $27.8(4.5)$ & $25.5(4.1)$ \\
\hline $\begin{array}{l}\text { Years of education beyond } \\
\text { primary school }\end{array}$ & $5.9(4.6)$ & $7.6(4.7)$ \\
\hline $\begin{array}{l}\text { Duration of AD since } \\
\text { diagnosis, months, } \\
\text { median [range] }\end{array}$ & $2.5[0.0-13.0]$ & $0.0[0.0-25.0]$ \\
\hline \multicolumn{3}{|l|}{ ApoE $\varepsilon 4$ carrier, n $(\%)$} \\
\hline No & $8(50.0)$ & $15(83.3)$ \\
\hline Yes & $8(50.0)$ & $3(16.7)$ \\
\hline Unknown & 0 & 3 \\
\hline Total MMSE score & $25.4(2.5)$ & $24.3(2.9)$ \\
\hline
\end{tabular}

OLE, open-label extension; RCT, randomized controlled trial; AD, Alzheimer's disease; ApoE, Apolipoprotein E; BMI, body mass index; MMSE, Mini-Mental State Examination. Data are mean (standard deviation) unless stated otherwise. ${ }^{\dagger}$ At week 24 of the Souvenir II RCT / start of the OLE study. completed the RCT but did not enter the OLE are also provided in Table 1. For each of these populations, baseline characteristics were not significantly different between the control(-active) and active(-active) groups. In addition, there were no significant differences in baseline characteristics between the RCT and OLE study populations.

Forty-five patients $(22.4 \%)$ began taking AD medication after starting intervention in the OLE study: 9 patients $(8.7 \%)$ received donepezil in the controlactive group compared with 18 patients $(18.6 \%)$ in the active-active group ( $p=0.061$, Fisher's Exact test); $2(1.9 \%)$ received galantamine in the control-active group compared with $4(4.1 \%)$ in the active-active group ( $p=0.432$, Fisher's Exact test); and $6(5.8 \%)$ received rivastigmine in the control-active group compared with $6(6.2 \%)$ in active-active group $(p=1.000$, Fisher's Exact test). Ten patients $(9.6 \%)$ in the controlactive group and 6 patients $(6.2 \%)$ in the active-active group started using $\mathrm{AD}$ medication after completion of the OLE study ( $p=0.440$, Fisher's Exact test). There were no significant or relevant between-group differences in the initiation of other medications or nutritional supplements during the OLE study.

\section{Outcome parameters}

Safety

Table 2 summarizes the number and proportion of patients experiencing one or more AEs in the RCT and OLE. In total, 105 patients $(52.2 \%)$ experienced at least one AE during the OLE study; including 57 patients $(54.8 \%)$ with 115 AEs in the control-active group and 48 patients (49.5\%) with 74 AEs in the active-active group. The AE profile in the OLE study was comparable to the RCT, except for the occurrence of any AEs related to the gastrointestinal system and respiratory system, which was significantly lower in the OLE study compared to the RCT ( $p=0.005$ and $p=0.013$, respectively, Fisher's Exact test). There was no significant or relevant difference in the proportion of patients experiencing at least one $\mathrm{AE}$ in the subgroup of patients who started using AD medication during the OLE study (22 patients [48.9\%]) compared with patients who remained AD drug-naive (83 patients [53.2\%]).

The most frequent AEs in the OLE study included dizziness/vertigo (4.0\%), surgical intervention (2.5\%), diarrhea $(2.5 \%)$, hypercholesterolemia $(2.0 \%)$, hypertension $(2.0 \%)$, back pain $(2.0 \%)$, headache $(2.0 \%)$, and angina pectoris (2.0\%). Most AEs in the OLE study were of mild $(68.3 \%)$ or moderate $(22.2 \%)$ intensity, 
Table 2

Number $(\%)$ of patients experiencing one or more AEs, by affected body system ${ }^{\dagger}$

\begin{tabular}{|c|c|c|c|c|}
\hline Body system (example AEs) & $\begin{array}{c}\text { Control } \\
(n=129) \\
\text { RCT }\end{array}$ & $\begin{array}{c}\text { Control-Active } \\
(n=104) \\
\text { OLE }\end{array}$ & $\begin{array}{c}\text { Active } \\
(n=129) \\
\text { RCT }\end{array}$ & $\begin{array}{c}\text { Active-Active } \\
(n=97) \\
\text { OLE }\end{array}$ \\
\hline $\begin{array}{l}\text { Body as a whole } \\
\quad \text { (back pain, syncope, fatigue) }\end{array}$ & $20(15.5 \%)$ & $13(12.5 \%)$ & $11(8.5 \%)$ & $9(9.3 \%)$ \\
\hline $\begin{array}{l}\text { Central and peripheral nervous system disorders } \\
\text { (dizziness/vertigo, headache) }\end{array}$ & $18(14.0 \%)$ & $7(6.7 \%)$ & $11(8.5 \%)$ & $9(9.3 \%)$ \\
\hline $\begin{array}{l}\text { Gastrointestinal system disorders } \\
\quad \text { (diarrhea, dyspepsia, constipation, flatulence) }\end{array}$ & $30(23.3 \%)$ & $10(9.6 \%)$ & $22(17.1 \%)$ & $10(10.3 \%)$ \\
\hline $\begin{array}{l}\text { Metabolic and nutritional disorders } \\
\text { (hypercholesterolemia, weight decrease, weight increase) }\end{array}$ & $9(7.0 \%)$ & $3(2.9 \%)$ & $13(10.1 \%)$ & $6(6.2 \%)$ \\
\hline $\begin{array}{l}\text { Musculo-skeletal system disorders } \\
\text { (fracture, myalgia, skeletal pain) }\end{array}$ & $9(7.0 \%)$ & $7(6.7 \%)$ & $10(7.8 \%)$ & $5(5.2 \%)$ \\
\hline $\begin{array}{l}\text { Psychiatric disorders } \\
\text { (aggressive reaction, anorexia, anxiety, depression) }\end{array}$ & $16(12.4 \%)$ & $14(13.5 \%)$ & $15(11.6 \%)$ & $7(7.2 \%)$ \\
\hline $\begin{array}{l}\text { Respiratory system disorders } \\
\text { (bronchitis, pharyngitis) }\end{array}$ & $15(11.6 \%)$ & $6(5.8 \%)$ & $10(7.8 \%)$ & $1(1.0 \%)$ \\
\hline $\begin{array}{l}\text { Other } \\
\quad \text { (fall, surgical intervention) }\end{array}$ & $8(6.2 \%)$ & $7(6.7 \%)$ & $8(6.2 \%)$ & $3(3.1 \%)$ \\
\hline
\end{tabular}

OLE, open-label extension; RCT, randomized controlled trial; AE, adverse event. ${ }^{\dagger}$ Only affected body systems reported by at least $5 \%$ of patients in either group of the OLE population are shown. Adverse events occurring in less than 5\% of patients in either group were: application site disorders, cardiovascular disorders, hearing and vestibular disorders, heart rate and rhythm disorders, liver and biliary disorders, myo-, endo-, pericardial and valve disorders, neoplasm, platelet, bleeding and clotting disorders, red blood cell disorders, reproductive disorders (male), resistance mechanism disorders, skin and appendages disorders, urinary system disorders, vascular (extracardiac) disorders, vision disorders.

with no clinically relevant differences between the control-active group and the active-active group. Twelve $(10.4 \%)$ of the AEs were rated as severe in the control-active group compared with $5(6.8 \%)$ in the active-active group, of which none were considered to be related to the use of the study product by the investigator. The majority of AEs were rated as being 'not related' $(74.1 \%)$ or 'unlikely to be related' $(19.6 \%)$ to the study product. Eleven AEs (5.8\%) were considered to be 'possibly related' (4 [3.5\%] in the control-active group, 7 [9.5\%] in the active-active group). The most frequent of these were: weight decrease ( 3 events), flatulence ( 2 events), and anorexia ( 2 events). One AE, flatulence, in the control-active group was considered to be 'probably related' to the use of the product. There was no indication that AEs considered to be related to the use of the study product during the RCT intensified during the OLE study.

Twenty-one SAEs occurred in 19 patients during the study; 10 SAEs in 9 patients in the control-active group and 11 SAEs in 10 patients in the active-active group. No SAEs were considered to be related to the use of the study product by the investigator. Two patients discontinued the study due to SAEs (avascular bone necrosis in the control-active group and diverticula in the active-active group), and one patient in the controlactive group died due to a malignant lymphoma. No clinically relevant changes in laboratory safety measures and vital signs were observed: mean systolic blood pressure, diastolic blood pressure, and heart rate remained within normal limits.

\section{Intake adherence and product evaluation}

Overall product intake adherence during the OLE study was $95.7 \%$ (95\% Confidence Interval [CI] 94.7-96.7\%), without significant differences between the control-active and active-active groups (betweengroup difference; $t$-test: $\left.\mathrm{t}_{183}=1.36, p=0.174\right)$. When combined with the Souvenir II RCT, the overall 48-week intake adherence for the active-active group was $96.1 \%$ (95\% CI, 95.0-97.1\%). The high compliance was supported by the biochemical outcome parameters; erythrocyte DHA (Fig. 2A), EPA and plasma vitamin E levels (Fig. 2B) remained at consistently elevated levels in the active-active group and were significantly increased in the control-active group in the OLE phase (48-week versus 24-week; $3.13 \pm 1.94 \% \quad$ (mean \pm standard deviation), paired $t$-test: $\mathrm{t}_{91}=-15.41, \quad p<0.001$ [DHA]; $0.87 \pm 0.48 \%, \mathrm{t}_{91}=-17.42, p<0.001$ [EPA]; $7.97 \pm 6.34 \mu \mathrm{mol} / 1, \mathrm{t}_{91}=-12.05, p<0.001$ [vitamin E]). Moreover, plasma homocysteine levels significantly decreased in the active-active (48-week versus 24 -week; $-1.16 \pm 3.17 \mu \mathrm{mol} / \mathrm{l}$, paired $t$-test: $\left.\mathrm{t}_{84}=3.38, p=0.001\right)$ and in the control-active group (48-week versus 24-week; $-5.13 \pm 5.27 \mu \mathrm{mol} / \mathrm{l}$, paired $t$-test: $\left.\mathrm{t}_{91}=9.34, p<0.001\right)$. 
A

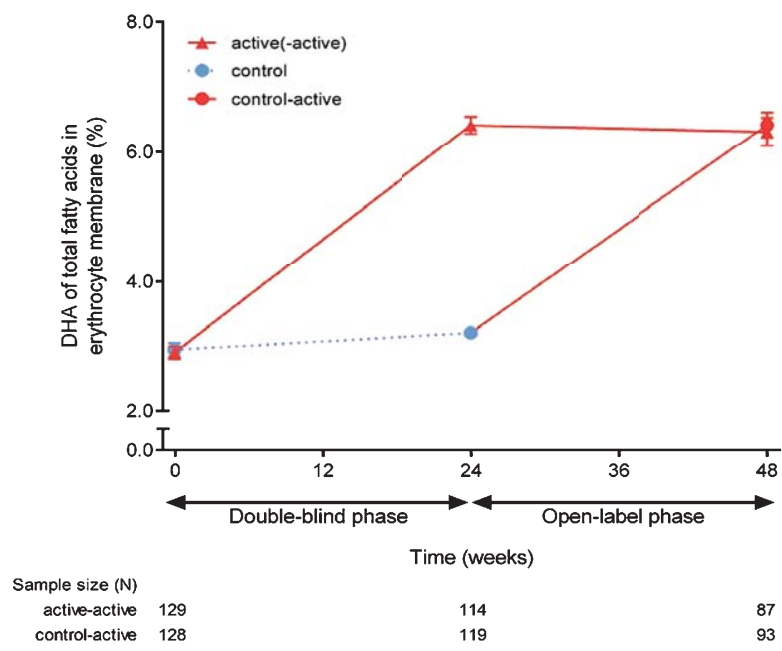

B

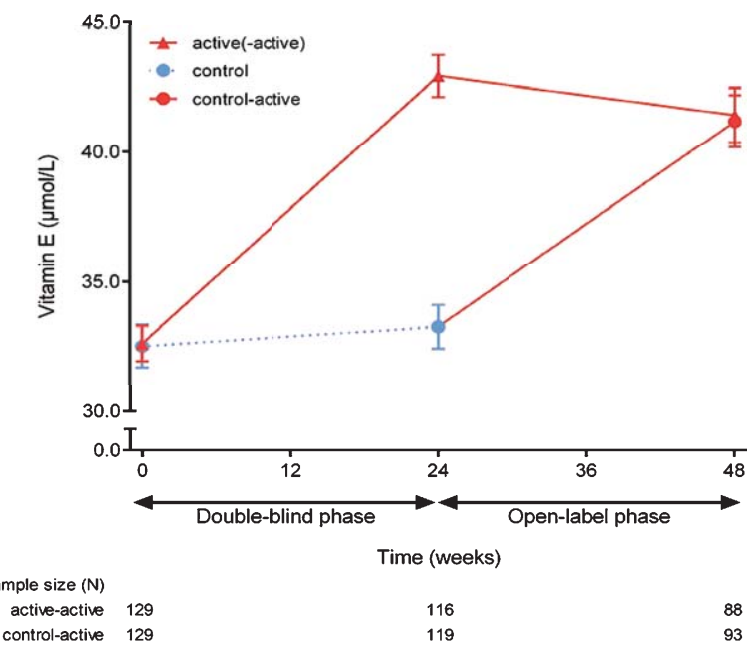

Fig. 2. A) Percentage docosahexaenoic acid (DHA) of total fatty acids in erythrocyte membrane. $24-48$ week change (paired $t$-test): $p=0.790$ active-active, $p<0.001$ control-active. B) Plasma vitamin E concentration ( $\mu$ mol/1). 24-48 week change (paired $t$-test): $p=0.187$ active-active, $p<0.001$ control-active. Data are mean and standard error (SE).

Responses from the product evaluation questionnaires, completed by patients with their caregivers, indicated that the taste of the study product was well appreciated, with no significant difference in mean ( \pm standard deviation) scores between the vanilla and strawberry flavor $(5.1 \pm 1.5$ compared with $4.9 \pm 1.6)$. These scores were comparable with the responses at the end of the RCT, as well as with the appreciation of the taste of the control products used in the RCT (vanilla: $5.5 \pm 1.4$, strawberry: $4.9 \pm 1.7$ ).

\section{Exploratory outcome measures}

NTB memory domain and individual item scores across the RCT and OLE are presented in Supplementary Table 1 . The fact that a proportion of the subjects in the RCT continued in the OLE resulted in an unbalanced design (different number of observations in the different cells of the design). In unbalanced designs, estimated marginal means are less likely to be biased than unadjusted means. Figure 3 shows the marginal means as estimated by the MMRM to illustrate the course of the NTB memory domain scores in the total 48 week period. In the 24 -week RCT, the primary outcome of the trajectory over time of the NTB memory domain score was statistically significantly increased in the active group versus control group, which was primarily driven by the changes from Week 12 to Week 24. In the OLE, the exploratory NTB memory domain score in the active-active group appeared to show con- tinued improvement (48-week versus 24-week scores; paired $t$-test: $\mathrm{t}_{81}=-2.28, p=0.025$; MMRM contrast: t $_{996}=2.43, p=0.015$ ). In addition, the change in NTB memory domain scores between the RCT baseline assessment and Week 48 was statistically significant in the active-active group (paired $t$-test: $\mathrm{t}_{82}=-6.63$, $p<0.001$; MMRM contrast: t996 $=5.87, p<0.001$ ). The control-active group showed a statistically significant increase of the NTB memory domain score after switching to the active product upon entry into the OLE (48-week versus 24-week scores; paired $t$-test: $\mathrm{t}_{86}=-2.72, p=0.008 ;$ MMRM contrast: $\mathrm{t}_{996}=2.71$, $p=0.007)$. All other between- and within group statistical comparisons mentioned in the section 'Statistical analyses' of the exploratory NTB memory domain score were not statistically significant. Results of the analyses of change in NTB memory domain score in the two exploratory key groups of interest are shown in Supplementary Figure 1 and described in the Supplementary Material.

No effect on the Disability Assessment for Dementia scale was observed in both the control-active and active-active group.

\section{DISCUSSION}

The results of this multi-center OLE following the Souvenir II RCT show that once-daily intake of Souvenaid is well tolerated with a favorable safety profile in patients with mild AD for up to 48 weeks. Product 
A

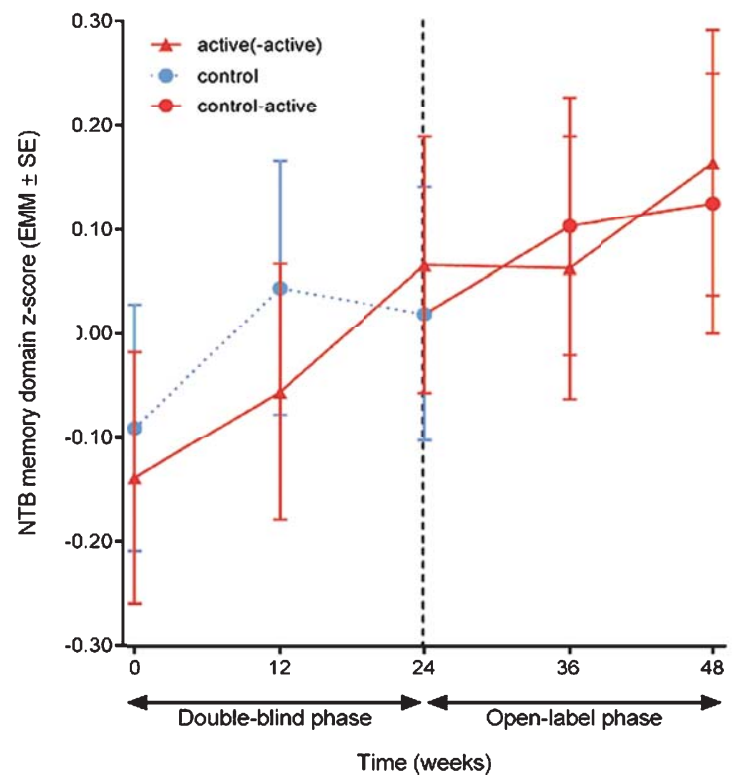

B

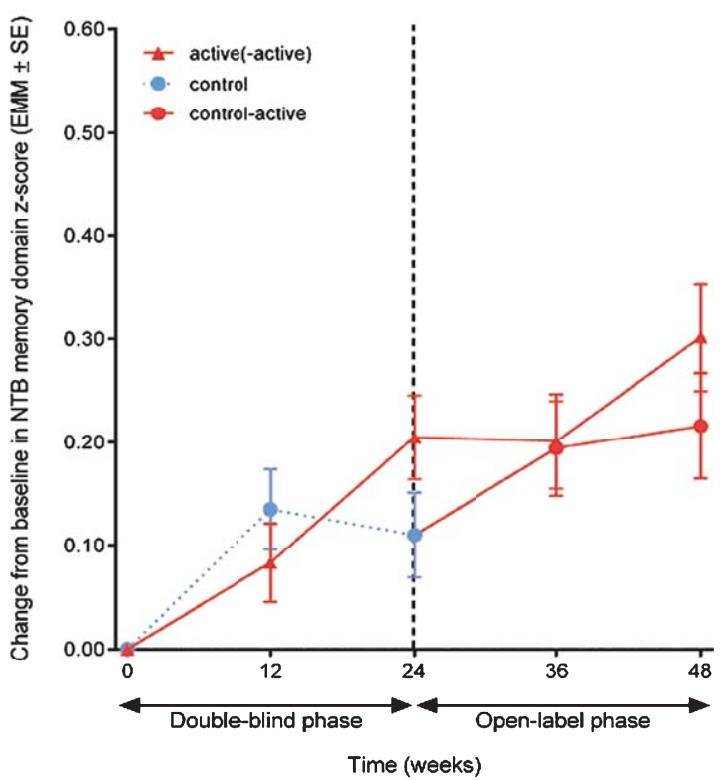

Fig. 3. NTB memory domain composite z-scores for both the double-blind RCT and OLE study period in (A) observed values and (B) change from baseline (RCT week 0). 24-48 week change for active-active group; paired $t$-test: $p=0.025$; MMRM: $p=0.015$ and for control-active group; paired $t$-test: $p=0.008$; MMRM: $p=0.007$. Data are estimated marginal mean (EMM) and standard error (SE).

intake adherence to Souvenaid was very high $(\geq 95 \%)$, reflecting its good tolerability and ease of use.

Souvenaid was well tolerated, with a similar percentage of patients experiencing AEs during the OLE as in the original RCT. Most AEs were of mild intensity and were not related to product intake. Overall, the type and frequency of AEs in the OLE were comparable to those reported in the RCT, while the overall percentage of patients experiencing gastrointestinal-related events during the OLE was even lower than during the RCT, which may suggest that these type of AEs decrease over time. Overall gastrointestinal AE rates in the current study were relatively low. In comparison, a Cochrane review on the use of acetylcholinesterase inhibitors in AD suggested that more gastrointestinal-related AEs occur in acetylcholinesterase inhibitor groups than in placebo [27]. However, these data are predominantly based on studies in mild-to-moderate AD, so any comparisons should be made with caution. Besides the favorable AE profile, laboratory safety parameters did not give any indication for AEs, and the discontinuation rate in the OLE was similarly low as in the RCT. There was no difference in the proportion of patients who experienced AEs between the $22 \%$ of patients receiving both AD medication and Souvenaid and those who remained $\mathrm{AD}$-drug naive. This extends the previous observations that Souvenaid was well tolerated when taken in conjunction with AD medication in mild-tomoderate $\mathrm{AD}$ [20]. Overall, the current data support results of previous studies and indicate that 48-week use of Souvenaid is safe and well-tolerated.

Good compliance to an intervention is of particular importance in clinical practice, where adherence to $\mathrm{AD}$ therapies is often poor and represents a major problem [28]. This OLE study reported a high product intake adherence ( $\geq 95 \%$ ), which is line with previous studies [18-20] and supported by biochemical data. Although intake adherence is likely to be higher in a clinical trial population compared with a real-world clinical setting, high compliance was further supported by the low rate of discontinuation and these observations highlight the potential of Souvenaid as a useful intervention for $\mathrm{AD}$ in clinical practice.

The main efficacy assessment from the RCT, the NTB memory domain z-score, was continued as an exploratory outcome measure in the OLE. While there are limits on the extent to which effectiveness can be assessed in an open-label study, the increase in the NTB memory score over a 48-week period is an encouraging result. Episodic verbal memory deficits are a clear characteristic of the cognitive deficits seen in early AD. The NTB memory measure helpfully employed to detect further improvements in memory during the OLE phase, following the statistically significant improve- 
ment observed during the RCT [19]. This finding is underlined by the improvement seen during the OLE in the control-active group, especially as patients were not aware of whether they initially received control or active intervention during the RCT. The observations on memory performance presented here extend the findings of the two previous RCTs $[18,19]$. However, it should be noted that the current exploratory results should be interpreted carefully, since the direction of the effect during the OLE phase was similar to the effect in this group when they used control product in the RCT phase [19], and correction for multiple testing was not applied.

There are limitations inherent to any open-label study that should be considered when interpreting the results. Firstly, although baseline characteristics were comparable between study groups, there is a potential for a selection bias on entry into the OLE. Secondly, OLE studies are primarily designed to provide longerterm safety and tolerability data applicable to routine clinical practice. As such, there is no control group and therefore efficacy cannot be adequately assessed. A limitation of this specific OLE study compared to the RCT is that there was no restriction to start with any nutritional supplements and AD medication. Even though an imbalance was observed in the number of patients in each group starting AD medication during the OLE, this appeared to be reversed after completion of the study, making it difficult to fully compare the RCT and the OLE studies.

In conclusion, the present open-label extension study to assess the safety, compliance, and exploratory effectiveness of Souvenaid in mild AD, showed that the use of Souvenaid for a total period of 48 weeks was well tolerated with a favorable safety profile and associated with a preliminary suggestion of continued improvement in memory performance. These findings warrant further investigation toward the long-term safety and efficacy of Souvenaid in a well-controlled, randomized, blinded setting, like the ongoing 24month EU funded LipiDiDiet study (Dutch Trial Register \#NTR1705) in prodromal AD.

\section{ACKNOWLEDGMENTS}

We sincerely thank the patients and their caregivers for their participation in the study and are indebted to the other investigators of the Souvenir II OLE study group: Dr. F.H. Bouwman; Dr. P.L.J. Dautzenberg; Dr. W.M.W. Sipers; Dr. D. van Asselt; Dr. M. Stevens; Dr. P. Tack; Dr. P. Bourgeois; Dr. E. Mulleners; Dr. med.
R. Horn; Prof. Dr. med. H-J. Gertz; Prof. Dr. med. J. Schröder; PD Dr. med. K-C. Steinwachs; Dr. P.G. Gil; Dr. M.R. Boada; Prof. P. Mecocci; Prof. G. Rodriguez; Dr. P-J. Ousset; Dr. M.M. Vercelletto; Prof. M.P.M. Ceccaldi.

Study design and conduct (collection, management, analysis and interpretation of the data, and preparation, review, and approval of the manuscript) were carried out in conjunction with the sponsor, Nutricia Research, on behalf of Nutricia Advanced Medical Nutrition. The sponsor also provided the study products and funding for the research and data collection.

Authors' disclosures available online (http://www.jalz.com/disclosures/view.php?id=2537).

\section{SUPPLEMENTARY MATERIAL}

The supplementary material is available in the electronic version of this article: http://dx.doi.org/10.3233/ JAD-141305.

\section{REFERENCES}

[1] Selkoe DJ (2002) Alzheimer's disease is a synaptic failure. Science 298, 789-791.

[2] Terry RD, Masliah E, Salmon DP, Butters N, DeTeresa R, Hill R, Hansen LA, Katzman R (1991) Physical basis of cognitive alterations in Alzheimer's disease: Synapse loss is the major correlate of cognitive impairment. Ann Neurol 30, 572-580.

[3] Scheff SW, Neltner JH, Nelson PT (2014) Is synaptic loss a unique hallmark of Alzheimer's disease? Biochem Pharmacol 88, 517-528.

[4] Sperling RA, Aisen PS, Beckett LA, Bennett DA, Craft S, Fagan AM, Iwatsubo T, Jack CR, Jr., Kaye J, Montine TJ, Park DC, Reiman EM, Rowe CC, Siemers E, Stern Y, Yaffe K, Carrillo MC, Thies B, Morrison-Bogorad M, Wagster MV, Phelps CH.(2011) Toward defining the preclinical stages of Alzheimer's disease: Recommendations from the National Institute on Aging-Alzheimer's Association workgroups on diagnostic guidelines for Alzheimer's disease. Alzheimers Dement 7, 280-292.

[5] DeKosky ST, Scheff SW (1990) Synapse loss in frontal cortex biopsies in Alzheimer's disease: Correlation with cognitive severity. Ann Neurol 27, 457-464.

[6] Wurtman RJ, Ulus IH, Cansev M, Watkins CJ, Wang L, Marzloff G (2006) Synaptic proteins and phospholipids are increased in gerbil brain by administering uridine plus docosahexaenoic acid orally. Brain Res 1088, 83-92.

[7] Sakamoto T, Cansev M, Wurtman RJ (2007) Oral supplementation with docosahexaenoic acid and uridine-5'monophosphate increases dendritic spine density in adult gerbil hippocampus. Brain Res 1182, 50-59.

[8] Holguin S, Martinez J, Chow C, Wurtman R.(2008) Dietary uridine enhances the improvement in learning and memory produced by administering DHA to gerbils. FASEB J 22, 3938-3946.

[9] Savelkoul PJ, Janickova H, Kuipers AA, Hageman RJ, Kamphuis PJ, Dolezal V, Broersen LM (2012) A specific multi-nutrient formulation enhances M1 muscarinic 
acetylcholine receptor responses in vitro. J Neurochem 120, 631-640.

[10] Wang L, Albrecht MA, Wurtman RJ (2007) Dietary supplementation with uridine-5' -monophosphate (UMP), a membrane phosphatide precursor, increases acetylcholine level and release in striatum of aged rat. Brain Res 1133, 42-48.

[11] de Bruin NM, Kiliaan AJ, de Wilde MC, Broersen LM (2003) Combined uridine and choline administration improves cognitive deficits in spontaneously hypertensive rats. Neurobiol Learn Mem 80, 63-79.

[12] Lopes da Silva S, Vellas B, Elemans S, Luchsinger J, Kamphuis P, Yaffe K, Sijben J, Groenendijk M, Stijnen T.(2013) Plasma nutrient status of patients with Alzheimer's disease: Systematic review and meta-analysis. Alzheimers Dement 10, 485-502.

[13] Olde Rikkert MGM, Verhey FR, Sijben JWC, Bouwman FH, Dautzenberg PLJ, Lansink M, Sipers WMW, van Asselt DZB, van Hees AMJ, Stevens M, Vellas B, Scheltens P (2014) Differences in nutritional status between very mild Alzheimer's disease patients and healthy controls. J Alzheimers Dis $\mathbf{4 1}$, 261-271.

[14] van Wijk N, Broersen LM, de Wilde MC, Hageman RJ, Groenendijk M, Sijben JW, Kamphuis PJ (2014) Targeting synaptic dysfunction in Alzheimer's disease by administering a specific nutrient combination. J Alzheimers Dis 38, 459-479.

[15] Jack CR, Knopman DS, Jagust WJ, Shaw LM, Aisen PS, Weiner MW, Petersen RC, Trojanowski JQ (2010) Hypothetical model of dynamic biomarkers of the Alzheimer's pathological cascade. Lancet Neurol 9, 119-128.

[16] Weintraub S, Wicklund AH, Salmon DP (2012) The neuropsychological profile of Alzheimer disease. Cold Spring Harb Perspect Med 2, a006171.

[17] Scheff SW, Price DA, Schmitt FA, Mufson EJ (2006) Hippocampal synaptic loss in early Alzheimer's disease and mild cognitive impairment. Neurobiol Aging 27, 1372-1384.

[18] Scheltens P, Kamphuis PJ, Verhey FR, Olde Rikkert MG, Wurtman RJ, Wilkinson D, Twisk JW, Kurz A. (2010) Efficacy of a medical food in mild Alzheimer's disease: A randomized, controlled trial. Alzheimers Dement 6, 1-10 e11.
[19] Scheltens P, Twisk J, Blesa R, Scarpini E, Vor Arnim C, Bongers A, Harrison J, Swinkels S, Stam C, De Waal H, Wurtman R, Wieggers R, Vellas B, Kamphuis P. (2012) Efficacy of Souvenaid in mild Alzheimer's disease: Results from a randomized, controlled trial. J Alzheimers Dis 31, 225-236.

[20] Shah RC, Kamphuis PJ, Leurgans S, Swinkels SH, Sadowsky CH, Bongers A, Rappaport SA, Quinn JF, Wieggers RL, Scheltens P, Bennett DA (2013) The S-Connect study: Results from a randomized, controlled trial of Souvenaid in mild-to-moderate Alzheimer's disease. Alzheimers Res Ther 5,59 .

[21] McKhann G, Drachman D, Folstein M, Katzman R, Price D, Stadlan EM (1984) Clinical diagnosis of Alzheimer's disease: Report of the NINCDS-ADRDA Work Group under the auspices of Department of Health and Human Services Task Force on Alzheimer's Disease. Neurology 34, 939-944.

[22] Folstein MF, Folstein SE, McHugh PR (1975) "Mini-mental state". A practical method for grading the cognitive state of patients for the clinician. J Psychiatr Res 12, 189-198.

[23] Harrison J, Minassian SL, Jenkins L, Black RS, Koller M, Grundman M. (2007) A neuropsychological test battery for use in Alzheimer disease clinical trials. Arch Neurol 64, 13231329.

[24] Gelinas I, Gauthier L, McIntyre M, Gauthier S (1999) Development of a functional measure for persons with Alzheimer's disease: The disability assessment for dementia. Am J Occup Ther 53, 471-481.

[25] Kuo K, Still R, Cale S, McDowell I (1997) Standardization (external and internal) of HPLC assay for plasma homocysteine. Clin Chem 43, 1653-1655.

[26] Krijt J, Vackova M, Kozich V. (2001) Measurement of homocysteine and other aminothiols in plasma: Advantages of using tris(2-carboxyethyl)phosphine as reductant compared with tri-n-butylphosphine. Clin Chem 47, 1821-1828.

[27] Birks J. (2006) Cholinesterase inhibitors for Alzheimer's disease. Cochrane Database Syst Rev, CD005593.

[28] Small G, Dubois B (2007) A review of compliance to treatment in Alzheimer's disease: Potential benefits of a transdermal patch. Curr Med Res Opin 23, 2705-2713. 